\title{
Assessment of Skeletal Class I Subjects of Uttarakhand using Beto Angle
}

\author{
Dr Dhananjay Rathod,' Dr GP Rathod,, Dr Pankaj Rathod,3 Dr Gazal Bisht4 \\ 'Asst Prof, Dept of Orthodontics, Nims Dental College, Jaipur, India \\ 2Prof, Dept of Oral pathology, Nobel Dental College, Biratnagar, Nepal \\ ${ }^{3}$ Asst Prof, Dept of Orthodontics, PDM Dental College, Bahadurgarh, India \\ ${ }^{4}$ Resident, Dept of Orthodontics, Seema Dental College, Rishikesh, India
}

Correspondence: Dr Dhananjay Rathod; Email: drdhananjayrathod@gmail.com

\section{ABSTRACT}

Objective: To evaluate and establish the norms for Class I subjects of Uttarakhand population using the beta angle.

Materials \& Method: The sample included pre-treatment lateral cephalograms of 100 subjects aged 18-30 years belonging to Uttarakhand ethnicity and possessing skeletal Class I malocclusion with pleasing profile. Beta angle measurement was performed and compared with Caucasian standards.

Result: No statistically significant difference was found in the beta angle values of Uttarakhand and Caucasian populations. Beta angle norms for Caucasian population can be applied for the Uttarakhand population.

Conclusion: Beta angle is relatively a stable parameter in population with different ethnicities.

Keywords: Beta Angle, Class I malocclusion, Uttarakhand population

\section{INTRODUCTION}

In 1931, cephalometric radiography was introduced in the field of orthodontics when the cephalograms of the head were presented through the authentic works of Broadbent in United States and Hofrath in Germany. Since its inception, cephalometry holds a critical parameter for diagnosis, treatment planning, assessment of treatment results and forecast of development. The institutionalization of scientific strategies prompted the cephalometric radiography as a fundamental diagnostic tool. A legitimate rule to clinicians through the accessibility of the cephalometric norms amid diagnosis and treatment arranging improved the outcome of facial and cephalometric characteristics in which the ethnic background of the patient is of prime consideration. ${ }^{2}$ Norms thus define the facial traits and establish the range of values that optimize the facial attractiveness.

Failure of the reference parameters of orthodontics in defining treatment plan prompted the development of another estimation called "beta angle" by Baik and Ververidou. ${ }^{3}$ Certain facial features such as prominent nose, cheek bone, and chins that best suit the patient in terms of size and arrangement must be evaluated; as these features represent the characteristics of the family or ethnicity. It has been recognized that various ethnic groups represent significant variations in craniofacial morphology and soft tissues. ${ }^{4,5}$ This justifies the need to study and develop the norms for population with unique facial morphology. Hence, the purpose of this study was to create the norms of beta angle for Uttarakhand subjects and its comparison with Caucasian standards.

\section{MATERIALS AND METHOD}

The study included a total of 100 subjects including 50 males and 50 females belonging to the Uttarakhand ethnicity of the age ranging between 18-30 years. The samples were selected by conducting the camps in various areas of Uttarakhand and screening was done at the out-patient department. Subjects possessing Class I molar and canine relationship, straight facial profile were included in the study along with the parameters such as no previous history of orthodontic treatment, minimal rotations, no spacing, and well aligned arches. The subjects were selected by the panel of judges consisted of orthodontists, prosthodontists and laymen. Informed consent was obtained from the participants to take lateral cephalogram. Mean values of the beta angle were obtained by tracing of the cephalographs. Radiographs were analyzed and fed in Dolphin imaging software 11.8 (Figure 1). The gender and ethnic variations were tested statistically using chi square test. 


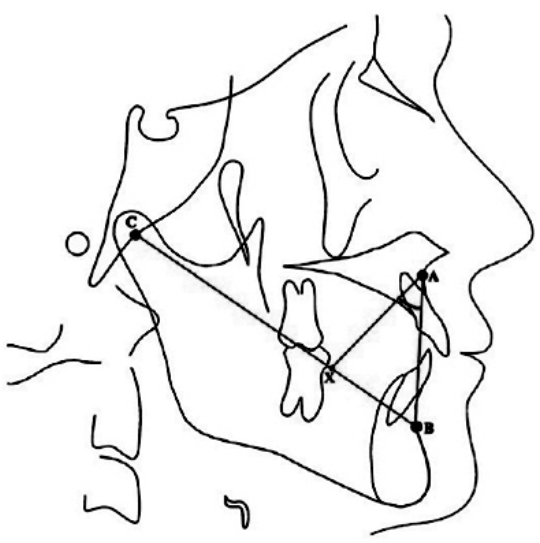

Figure 1: Beta Angle

RESULT

Table 1: Calculated values of $\beta$ angle for male and female subjects

\begin{tabular}{|c|c|c|c|c|c|c|}
\hline \multirow{2}{*}{ Parameter } & \multicolumn{2}{|c|}{ Male } & \multicolumn{2}{c|}{ Female } & \multirow{2}{*}{ Mean Difference } & $p$-Value \\
\cline { 2 - 7 } & Mean & SD & Mean & SD & & 0.425 (NS) \\
\hline Beta Angle & 28.63 & 4.41 & 30.69 & 2.87 & 2.40 & 0.47 \\
\hline
\end{tabular}

NS: Not significant

Table 2: Comparison of $\beta$ angle between Uttarakhand and Caucasian samples

\begin{tabular}{|c|c|c|c|c|c|c|}
\hline \multirow{2}{*}{ Parameter } & \multicolumn{2}{|c|}{ Uttarakhand } & \multicolumn{2}{|c|}{ Caucasian } & \multirow{2}{*}{ Mean Difference } & \multirow{2}{*}{$\boldsymbol{p}$-Value } \\
\cline { 2 - 7 } & Mean & SD & Mean & SD & & \\
\hline Beta Angle & 29.63 & 3.69 & 31.1 & 2.0 & 3.14 & 0.23 (NS) \\
\hline
\end{tabular}

NS: Not significant

\section{DISCUSSION}

An orthodontic treatment planning depends vastly on the accuracy of measurement of the interjaw relationships in sagittal plane. The mean values obtained showed that there are statistically no significant differences in the average values of the male and female subjects in uttarakhand population sample.

Various authors reported ethnic differences in cephalometric variables between the populations belonging to Asian and Caucasian ethnicity. ${ }^{2-6}$ However, the correlation of the mean values for beta angle in subjects possessing a Class I malocclusion of Uttarakhand ethnicity and Caucasian population groups concludes the stability of the beta angle irrespective of the craniofacial morphology found in different ethnic groups.

\section{CONCLUSION}

The present study can be concluded as follows:

- No statistical significant difference for the beta angle values exists between male and female subjects belonging to Uttarakhand ethnicity possessing skeletal Class I malocclusion.

- The beta angle is relatively stable cephalometric parameter among Caucasian as well as Uttarakhand populations; thus the norms of caucasian population can be applied for Uttarakhand subjects.

- Beta angle can be used an effective and alternate method for assessing the sagittal discrepancies as compared to the traditional methods.

\section{OJN}

\section{REFERENCES}

1. Paixao M, Costa M, Vogel C, Arauj T. Comparative study between manual and digital cephalometric tracing using Dolphin Imaging software with lateral radiographs. Dent Press J Orthod. 2010; 15(6):123-30.

2. Kalha AS, Latif A, Govardhan SN. Soft tissue cephalometric norms in South Indian ethnic population. Am J Orthod Dentofac Orthop. 2008; 133:876-81.

3. Baik CY, Ververidou M. A new approach of assessing sagittal discrepancies: The Beta angle. Am J Orthod Dentofac Orthop 2004; 126:100-5.

4. Almyra M, Naranjilla S, Janson IR. Cephalometric floating norms as a guide toward a harmonious individual craniofacial pattern among Filipinos. Angle Orthod. 2009; 79:6:1 162-8.

5. Wei SHY. A roentgenographic cephalometric study of prognathism in Chinese males and females. Angle Orthod. 1968; 38:4:305-20.

6. Hussels W, Nanda RS. Analysis of factors affecting angle ANB. Am J Orthod. 1984; 85:41 1-23. 